\title{
Risk Assessment of Recreational Noise-Induced Hearing Loss from Exposure through a Personal Audio System-iPod Touch
}

DOI: $10.3766 /$ jaaa. 17140

Kamakshi V. Gopal*

Liana E. Mills*

Bryce S. Phillips*

Rajesh Nandy ${ }^{\dagger}$

\begin{abstract}
Background: Recreational noise-induced hearing loss (RNIHL) is a major health issue and presents a huge economic burden on society. Exposure to loud music is not considered hazardous in our society because music is thought to be a source of relaxation and entertainment. However, there is evidence that regardless of the sound source, frequent exposure to loud music, including through personal audio systems (PAS), can lead to hearing loss, tinnitus, difficulty processing speech, and increased susceptibility to age-related hearing loss.

Purpose: Several studies have documented temporary threshold shifts (TTS) (a risk indicator of future permanent impairment) in subjects that listen to loud music through their PAS. However, there is not enough information regarding volume settings that may be considered to be safe. As a primary step toward quantifying the risk of RNIHL through PAS, we assessed changes in auditory test measures before and after exposure to music through the popular iPod Touch device set at various volume levels.
\end{abstract}

Research Design: This project design incorporated aspects of both between- and within-subjects and used repeated measures to analyze individual groups.

Study Sample: A total of 40 adults, aged 18-31 years with normal hearing were recruited and randomly distributed to four groups. Each group consisted of five males and five females.

Data Collection and Analysis: Subjects underwent two rounds of testing (pre- and postmusic exposure), with a 30-min interval, where they listened to a playlist consisting of popular songs through an iPod at $100 \%, 75 \%, 50 \%$, or $0 \%$ volume (no music). Based on our analysis on the Knowles Electronic Manikin for Acoustic Research, with a standardized 711 coupler, it was determined that listening to the playlist for $30 \mathrm{~min}$ through standard earbuds resulted in an average level of $97.0 \mathrm{dBC}$ at $100 \%$ volume, $83.3 \mathrm{dBC}$ at $75 \%$ volume, and $65.6 \mathrm{dBC}$ at $50 \%$ volume. Pure-tone thresholds from $500-8000 \mathrm{~Hz}$, extended high-frequency pure tones between $9-12.5 \mathrm{kHz}$, and distortion product otoacoustic emissions (DPOAE) were obtained before and after the 30-min music exposure. Analysis of variance (ANOVA) was performed with two between-subjects factors (volume and gender) and one within-subjects factor (frequency). Change (shift) in auditory test measures was used as the outcome for the ANOVA.

Results: Results indicated significant worsening of pure-tone thresholds following music exposure only in the group that was exposed to $100 \%$ volume at the following frequencies: $2,3,4,6$ and $8 \mathrm{kHz}$. DPOAEs showed significant decrease at 2000 and $2822 \mathrm{~Hz}$, also only for the $100 \%$ volume condition. No significant changes were found between pre- and postmusic exposure measures in groups exposed to $75 \%$, $50 \%$, or $0 \%$ volume conditions. Follow-up evaluations conducted a week later indicated that pure-tone thresholds had returned to the premusic exposure levels.

*Department of Audiology and Speech-Language Pathology, University of North Texas, Denton, TX; $†$ Department of Biostatistics and Epidemiology, University of North Texas Health Science Center, Fort Worth, TX

Corresponding author: Kamakshi V. Gopal, Department of Audiology and Speech-Language Pathology, University of North Texas, Denton, TX 76203; Email: gopal@unt.edu

This investigation was supported by a grant from the Texas Speech-Language-Hearing Foundation. 
Conclusions: These results provide quantifiable information regarding safe volume control settings on the iPod Touch with standard earbuds. Listening to music using the iPod Touch at $100 \%$ volume setting for as little as 30 min leads to TTS and worsening of otoacoustic emissions, a risk for permanent auditory damage.

Key Words: iPod, personal audio systems, pure-tone thresholds, recreational noise-induced hearing loss, temporary threshold shift

\begin{abstract}
Abbreviations: $A N O V A=$ analysis of variance; DPOAE $=$ distortion product otoacoustic emissions; $\mathrm{IRB}=$ Institutional Review Board; KEMAR = Knowles Electronic Manikin for Acoustic Research; $\mathrm{NIOSH}=$ National Institute for Occupational Safety and Health; OSHA = Occupational Safety and Health Administration; PAS = personal audio systems; PTS = permanent threshold shift; $\mathrm{RNIHL}=$ recreational noise-induced hearing loss; TEOAE = transient-evoked otoacoustic emissions; TTS $=$ temporary threshold shifts
\end{abstract}

\section{INTRODUCTION}

$\mathrm{R}$ ecreational noise-induced hearing loss (RNIHL) refers to hearing loss resulting from exposure to community experiences or activities such as firing guns, playing musical instruments, attending concerts, involvement in motorsports, community noise from airports or construction sites, commuter noise, and even listening to personal audio systems (PAS); for example, iPods, mP3 players, and cell phones (Fligor, 2011; Rawool, 2012). The World Health Organization (2015) estimates that 1.1 billion young people between the ages of 12-35 years old worldwide are at risk for hearing loss from unsafe use of personal audio devices and exposure to damaging levels of sound at noisy entertainment venues.

Exposure to loud levels of noise, even for a short duration, can lead to mechanical trauma and metabolic stress in the organ of Corti (Henderson et al, 2006). Ryan et al (2014) showed that the loss of threshold sensitivity depends on the initial shift from exposure, and the degree of recovery is based on the characteristics of the noise exposure, including, intensity, duration, frequency, and the individual characteristics of the person exposed. Threshold shifts that recover to baseline levels within weeks after exposure are termed temporary threshold shifts (TTS). However, more injurious exposures from continuous or repeated encounters can produce threshold sensitivity losses that may not recover (Eldredge et al, 1973; Ryan and Bone, 1978; LonsburyMartin et al, 1987), thus, leading to a measurable permanent threshold shift (PTS). TTS results often show worsened hearing thresholds within one to two octaves above the source frequency of the noise. After repeated exposure, a notched pattern begins to formulate in the $2-4 \mathrm{kHz}$ region, eventually leading to PTS that represents a permanent hearing loss. When PTS occurs, it leads to long-term communication difficulties, especially if the hearing loss is not addressed and is allowed to progress. In mice experiments, Kujawa and Liberman (2009) showed that even in cases where the induced TTS recovered and no hair cells were lost, there was acute loss of synapses between inner hair cells and spiral ganglion neurons innervating them, thus, setting the stage for neurodegeneration. More recently, Liberman and Kujawa (2017) argued that well before any hearing loss can be documented from noise exposure, synaptic communication between inner hair cells and a subset of cochlear nerve fibers are permanently damaged. This condition, termed cochlear synaptopathy, is where there is neural degeneration and dysfunction of synapses even without hair cell loss. This in turn can lead to a variety of perceptual problems, including tinnitus, hyperacusis, and difficulty understanding speech in noisy situations.

A wide variety of hobbies can expose people to unsafe levels of noise, leading to cochlear synaptopathy. An ever increasing and commonly popular activity is the use of the PAS. Since the introduction of the PAS, such as personal radios, cassette players, CD players, and MP3 players, there has been an increase in access to sound exposure at an individual level. There are now many more listening methods and an even larger number of products and styles that are available. The possibility of hearing damage from PAS usage among adolescents and young adults has been a cause of concern for many years (Serra et al, 2005). Several studies have indicated that adolescents and young adults who regularly listen to music through their PAS devices have significantly elevated pure-tone thresholds, weaker otoacoustic emissions, or both (Peng et al, 2007; Kim et al, 2009; Le Prell et al, 2011; Sulaiman et al, 2013). By contrast, some studies have reported no such differences (Pugsley et al, 1993; Trzaskowski et al, 2014). However, it must be noted that methodological differences, including the type of listening device investigated and the variability in the volume-level settings, play a significant role in the outcomes of these studies.

In a recreational setting, multiple studies have shown that individuals exposed to recreational noise on a regular basis have other auditory-related symptoms such as tinnitus, hyperacusis, and difficulty understanding speech in noise (Chung et al, 2005; Williams, 2005; Goggin et al, 2008; Zocoli et al, 2009; McNeill et al, 2010; Muhr and Rosenhall, 2010; Derebery et al, 2012; Gilles et al, 2012; Muchnik et al, 2012; Feder et al, 2013; Gilles et al, 2013; Sulaiman et al, 2013; 
Degeest et al, 2014; Balanay and Kearney, 2015; Keppler et al, 2015; Silvestre et al, 2016). Various researchers have reported on PAS use and the risks involved in high-intensity and long duration exposures, and have recommended further education and public awareness (Bulbul et al, 2009; Hoover and Krishnamurti, 2010; Vogel et al, 2010; Henderson et al, 2011; Vogel et al, 2011; Danhauer et al, 2012; Fligor et al, 2014). Sulaiman et al (2013) showed that the PAS users had significantly higher pure-tone thresholds at extended high frequencies and significantly lower distortion product otoacoustic emissions (DPOAE) and transient-evoked otoacoustic emissions (TEOAEs). They also found that longer PAS usage corresponded with poorer hearing thresholds. Similarly, several studies have documented decreased otoacoustic emissions in PAS exposures (LePage and Murray, 1998; Montoya et al, 2008) and showed that decreased otoacoustic emissions may perhaps precede the occurrence of music-induced hearing loss (Bhagat and Davis, 2008).

Across the world, the popularity of PAS has grown, as devices have become smaller and more accessible. Many college students are at risk of music exposure levels high enough to initially cause TTS, which eventually can lead to PTS. Peng et al (2007) showed that $14.1 \%$ of university students in their study had hearing loss at standard clinical frequencies following PAS exposures, even after a 24-hour recovery period. Hoover and Krishnamurti (2010) reported $66 \%$ of college students listened to their PAS three or more days per week, approximately, $10 \%$ of the students listened at $75-100 \%$ volume, $36.6 \%$ reported listening at full volume in certain situations, and only half reported concerns of hearing loss following listening periods. It should be noted that college students may be at risk for RNIHL not only just from PAS usage, but also from additional routine exposure to loud noise at bars, clubs, discotheques, concerts, and music classes (Hanson and Fearn, 1975; Trask et al, 2006; Peng et al, 2007; Holland, 2008; Torre, 2008; Danhauer et al, 2009; Kumar et al, 2009; Hoover and Krishnamurti 2010; McNeill et al, 2010; Le Prell et al, 2011; Levey et al, 2011; Le Prell et al, 2012; Gopal et al, 2013; Le Prell et al, 2013; Degeest et al, 2014; Spankovich et al, 2014; Balanay and Kearney, 2015; Tronstad and Gelderblom, 2016; Washnik et al, 2016).

RNIHL is a major health issue and presents a huge economic burden on society. Determining the effects of specific output levels from various systems is a complicated task, however, one that is desperately needed for regulatory purposes and prevention of RNIHL. The recommended exposure limit for noise is 85 decibels of A-weighted noise (dBA) over an eight-hour time-weighted average, with a $3-\mathrm{dB}$ exchange rate that either halves or doubles the permissible exposure time based on the decibel level (NIOSH, 1998). The 85-dBA limit assumes daily exposure more than eight hours over a period of 40 years. NIOSH (1998) found that using their recommended exposure limit of $85 \mathrm{dBA}$ versus $90 \mathrm{dBA}$ resulted in a $17 \%$ reduction is the risk of developing occupational noise-induced hearing loss. Although this was originally created for industrial noise exposure settings, studies in the area of music-induced hearing loss have adopted the same formula. The National Institute for Occupational Safety and Health (NIOSH) exposure limit is the most widely used formula for calculating the daily noise dose (Jiang et al, 2016). To clearly link PAS usage and risk of hearing loss, and to encourage safe listening habits in the general public, well-controlled studies are needed. Consistent with this notion, we designed a study with the aim of quantifying the risk of hearing loss from the widely used Apple iPod Touch listening device (Apple Inc., Cupertino, CA) with its standard earbuds. The goals of this study were to (a) assess the risk of hearing loss from iPods set at various volume levels and (b) identify safe listening levels that can support regulatory policies. The risk of hearing loss was assessed by measuring changes in hearing thresholds and DPOAEs in young adults exposed to controlled music levels for $30 \mathrm{~min}$ through an iPod Touch with standard earbuds.

\section{METHODS}

$T$ his study was approved by the university institutional review board (IRB). Participants were recruited from within and around the university campus. Based on the inclusion criteria, our subject pool comprised young adults with no complaints of hearing loss, no history of neurological disorders, no use of medications that may affect cognitive function, history of regular usage of a PAS at maximum volume for at least 30 min once a week, and no exposure to occupational noise exposure. All subjects exhibited a willingness to take part in audiological testing twice, both pre- and postmusic exposure, and agreed to listen to music at loud levels, possibly at maximum $(100 \%)$ volume. All subjects signed the IRB approved consent form before the collection of data.

\section{Subjects and Grouping}

A total of 40 subjects were included in this study. The subjects were randomly placed in one of four groups consisting of ten subjects: Group 1 consisted of subjects that listened to music at $100 \%$ volume level, Group 2 listened to music at $75 \%$ volume level, Group 3 listened to music at $50 \%$ volume level, and Group 4 did not listen to music (0 volume level).

\section{Procedure}

Before any testing, subjects filled out an adult case history form along with an additional questionnaire 
(see Appendix) that was used to elicit more details regarding the individuals' auditory symptoms, music exposure history such as their music-listening habits, and their willingness to change their listening habits if counseled. After obtaining assurance from subjects that they had not been exposed to loud music or noise in the last 24 hours, testing commenced. First, otoscopy was completed on all subjects. If cerumen was found that would affect probe microphone measures, it was removed with a sterilized curette. This was followed by premusic exposure testing that included the following tests: tympanograms (GSI TympStar; Grason-Stadler, Eden Prairie, MN), pure-tone thresholds (Madsen Astera; GN Otometrics, Schaumburg, IL), and DPOAEs (IHS Smart DPOAE; Intelligent Hearing Systems, Miami, FL). All testing was carried out in a double-walled sound-treated booth using calibrated equipment. Using the modified HughsonWestlake procedure, air-conduction thresholds were obtained at $500 \mathrm{~Hz}, 1,2,3,4,6$, and $8 \mathrm{kHz}$. Extended high-frequency testing included $9,10,11.2$, and 12.5 $\mathrm{kHz}$. DPOAEs were recorded and assessed by simultaneously presenting two primary tones (frequencies $f 1$ and $f 2$ ) at an $f 2: f 1$ ratio of 1.22 . The DPOAE data were obtained for the frequencies of 499, 1003, 1409, 2000, 2822,3991 , and $5649 \mathrm{~Hz}$, with the intensity levels ( $L 1$ and $L 2$ ) set to $65 / 55 \mathrm{~dB}$ SPL.

\section{Music Exposure}

Following the premusic exposure testing, subjects assigned to the music-listening groups (Groups 1, 2, and 3) listened to music for $30 \mathrm{~min}$, and subjects in Group 4 did not listen to any music during that period. For subjects in the music-listening groups, a probe microphone from a real-ear measurement system (Verifit; Audioscan, Dorchester, Ontario, Canada) was placed within $5 \mathrm{~mm}$ of the tympanic membrane and verified by otoscopy. An Apple iPod Touch (6th generation) was chosen as the music device because of its popularity as a music-listening device. Standard Apple Earpod earphones (Apple Inc.) fitted with Earhoox (Earhoox, Orlando, FL) were used to deliver music and were sanitized each time before each use. Earhoox ensured that the Earpods would not fall out of the ear or move the probe microphone during the 30-min music exposure. Songs used for the study were ripped from CDs (Now That's What I Call Music! 53 and 54; Sony Music Entertainment; New York City, NY) into WAV format using Windows Media Player. The songs were chosen based on their high rankings in the Billboard Top 100 during March 2015. The songs were then digitally altered using Audacity 2.0.5, a free audio recording and editing software (Audacity Team, Pittsburgh, PA). First, songs were merged into one track and then silent periods of more than one second were truncated. The songs were then dynamically compressed using the Dynamic Com- pressor 1.2.6 plug-in. These changes ensured consistent music exposure and decreased variability in intensity between songs. There was no perceived difference in the songs after these changes. The playlist was exactly 30 min in duration and included nine songs.

To ensure safety and Occupational Safety and Health Administration/NIOSH compliance, and obtain IRB approval, the loudness levels for the playlist were measured using a Knowles Electronics Manikin for Acoustic Research (KEMAR) head-and-torso simulator fitted with Zwislocki artificial ears. The iPod earphones were coupled to standard adult ear simulators on the KEMAR and connected to a sound level meter (Larson-Davis 824; PCB Piezotronics, Inc., Provo, UT). Based on the analysis, it was identified that the output level for $100 \%$ volume (Group 1 exposure level) was $97.0 \mathrm{dBC}$ (range 78102.4), output for $75 \%$ volume (Group 2 exposure level) was $83.3 \mathrm{dBC}$ (range 60.8-88.4), and output for 50\% volume (Group 3 exposure level) was $65.6 \mathrm{dBC}$ (range 49.3-71.7). None of these levels exceeded the NIOSH or Occupational Safety and Health Administration standards for time-weighted maximum noise exposure limits.

Real-ear measurements were obtained during music exposure from all subjects in Groups 1, 2, and 3 and were converted to $\mathrm{dBA}$ values using a clinical probe microphone technique suggested by Portnuff et al (2013). Song times were then broken down into seconds, and using Random.org (Haahr, 2016), each song was assigned a 12 -sec test sample. The subjects were instructed to not touch the earbuds, iPod, or alter the music in any way, including pausing, volume changes, and/or song changes. They were also reminded that they could discontinue participation at any point, if the volume level became uncomfortable. After the playlist ended, pure-tone thresholds and DPOAEs were obtained a second time in random order. The subjects were also asked about any ear- or hearing-related symptoms they may have experienced soon after listening to the playlist. The subjects were then asked to return for follow-up testing within a week, where puretone thresholds were reevaluated.

Changes between pre- and postexposure test results were obtained for each subject separately and averaged across both ears at each frequency. Means and standard deviation scores were obtained for each group. Repeated measures analysis of variance was performed with outcome measures as the within-subject factor, and volume and gender as between-subjects factors.

\section{RESULTS}

ll subjects in this study were adults between the
ages of $18-31$. The mean ages for each group were $21.30 \pm 2.3$ (Group 1), $21.2 \pm 4.24$ (Group 2), $21.8 \pm 2.82$ (Group 3), and 24.8 \pm 3.2 (Group 4). Each group had five males and five females. All had normal otoscopic results, 
normal-hearing thresholds at frequencies between 250 and $8000 \mathrm{~Hz}$, and type A tympanograms in both ears.

\section{Questionnaire}

Questionnaire responses (Table 1) collected from the subjects gave information on their listening habits, earrelated problems, and willingness to change their habits. Of the 40 individuals that served as subjects in this study, 30\% had preexisting tinnitus. All participants reported using commercially available PAS, with a majority of them using Apple iPhones/Apple iPods with Apple earbuds. About $90 \%$ of the participants reported listening to music through their device for more than five years, and $82.5 \%$ reported listening to their devices three or more times per week. Most participants (85\%) reported listening to music $\geq 3$ hours per week, seven participants reported listening to $\geq 3$ hours of music continuously in one setting, and the remaining participants reported listening to music $\leq 2$ hours in one setting. More than $75 \%$ reported experiencing a variety of auditory symptoms such as ringing/buzzing, ear fullness, hearing loss or muffled hearing, soreness in the ears, limited concentration, or decreased tolerance or annoyance with certain environmental sounds after listening to music through their PAS. All participants reported listening to their devices while doing other activities such as walking, jogging, studying, and exercising. When the participants were asked if they were concerned about possible hearing loss from their listening device, $63 \%$ were found to be slightly/moderately concerned, but none were extremely concerned. An interesting finding was that $93 \%$ of these subjects were willing to decrease volume on their PAS and $72.5 \%$ of the subjects were willing to decrease listening time if educated on the risk of hearing loss.

When asked what the best way to provide information to the public is, a majority of the participants $(82.5 \%)$ said the internet. When asked what information would be the most valuable to provide on a website about listening devices, $60 \%$ said appropriate volume levels would be the most beneficial.

\section{Real-Ear Measures}

Every participant in Groups 1, 2, and 3 was tested at the same 20 sample times during the real-ear measurement, one sample for the right ear and one for the left, during each of the ten songs in the stimulus track. For example, the outputs in all participants were measured at 1:02 min for the right ear and 1:35 min for the left ear during the first song. Because of the limitation of the available equipment, real-ear recordings were obtained consecutively rather than simultaneously, meaning that songs were sampled at different points during each song for right and left ears. In selecting track samples for real-ear measures, all samples times within each song were chosen randomly for each ear using random. org. Because the samples were obtained randomly and at different parts of the song, slight differences in overall dBA across samples were expected. Average overall dBA across participants for all song samples showed right and left ear exposures of $97.7( \pm 3.57)$ and $98.3( \pm 3.89) \mathrm{dBA}$ for Group 1, $83.4( \pm 2.04)$ and $83.3( \pm 4.04) \mathrm{dBA}$ for Group 2, and $69.9( \pm 3.17)$ and $69.4( \pm 3.48)$ for Group 3, respectively. The real-ear measures obtained from the music-listening groups while listening to the playlist during the study are shown in Figure 1. Recorded levels averaged across right and left ears were as follows: Group 1: $97.9( \pm 3.63) \mathrm{dBA}$; Group 2: $83.3( \pm 3.11) \mathrm{dBA}$; and Group 3: $69.6( \pm 3.18)$ $\mathrm{dBA}$. These levels were within $1-4 \mathrm{~dB}$ of the loudness levels measured on KEMAR for the same song list set at $100 \%, 75 \%$, and $50 \%$, respectively.

\section{Pure-Tone Thresholds}

Shifts in thresholds for regular clinical frequencies, $500-8000 \mathrm{~Hz}$, as well as for the extended high frequencies, 9000-12500 Hz, are shown in Figure 2. The shifts/ changes in pure-tone thresholds following music exposure were most often seen in the mid-frequencies, especially for Group 1 ( $100 \%$ volume condition). Statistically significant shifts were seen only in Group 1 at frequencies $2000-8000 \mathrm{~Hz}$ and are denoted with an asterisk in

Table 1. Summarized Questionnaire Responses from Study Subjects Based on Group Membership

\begin{tabular}{|c|c|c|c|c|}
\hline & $\begin{array}{c}\text { Group } 1 \\
(100 \%)\end{array}$ & $\begin{array}{c}\text { Group } 2 \\
(75 \%)\end{array}$ & $\begin{array}{c}\text { Group } 3 \\
(50 \%)\end{array}$ & $\begin{array}{l}\text { Group } 4 \\
\text { (Control) }\end{array}$ \\
\hline Mean age in years (standard deviation) & $\begin{array}{l}21.30 \\
(2.31)\end{array}$ & $\begin{array}{l}21.20 \\
(4.24)\end{array}$ & $\begin{array}{l}21.80 \\
(2.82)\end{array}$ & $\begin{array}{l}24.80 \\
(3.19)\end{array}$ \\
\hline Preexisting tinnitus & $20 \%$ & $40 \%$ & $40 \%$ & $20 \%$ \\
\hline Apple iPod usage & $70 \%$ & $40 \%$ & $50 \%$ & $60 \%$ \\
\hline Weekly listening of $3+$ Days & $100 \%$ & $100 \%$ & $70 \%$ & $60 \%$ \\
\hline Auditory symptoms* & $80 \%$ & $100 \%$ & $60 \%$ & $70 \%$ \\
\hline Willing to decrease volume & $90 \%$ & $90 \%$ & $100 \%$ & $90 \%$ \\
\hline Willing to decrease listening time & $80 \%$ & $60 \%$ & $80 \%$ & $70 \%$ \\
\hline
\end{tabular}

$\mathrm{SD}=$ standard deviation.

*Includes symptoms of ear fullness, muffled hearing, sore ears, or decreased tolerance to certain sounds. 


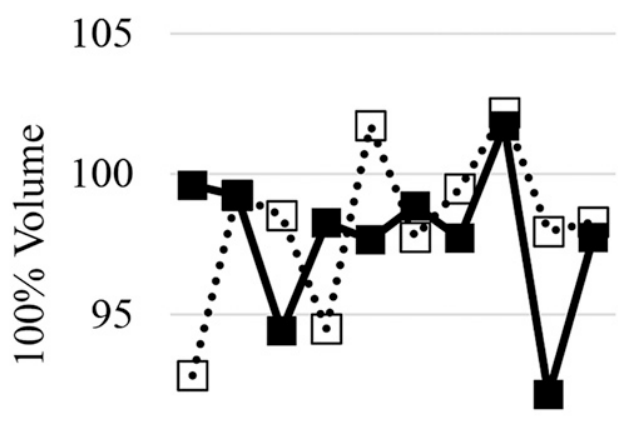

90
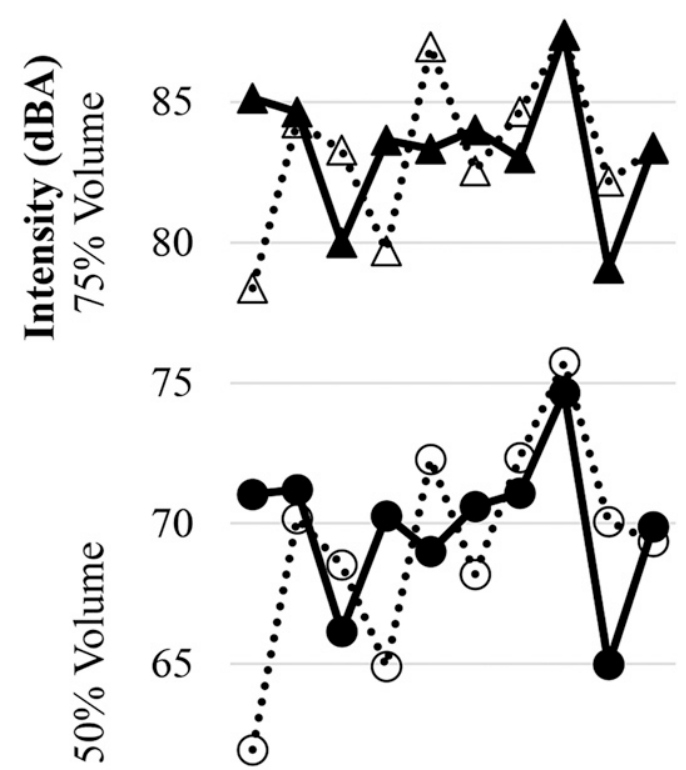

60

$$
\begin{array}{lllll}
12345678 & 5610 \\
\text { Songs } & &
\end{array}
$$$$
\begin{aligned}
& \longrightarrow \text { A-Right } \cdot \bullet \cdot \cdot \text { A-Left } \\
& \longrightarrow \text { B-Right } \cdot \cdots \bullet \cdot \cdot \text { B-Left } \\
& \longrightarrow \text { C-Right } \cdot \cdots \cdot \cdot \text { C-Left }
\end{aligned}
$$

Figure 1. Average real-ear measures for each of the three music exposed groups. " $R$ " is right ear, "L" is left ear, Group 1 is $100 \%$ volume, Group 2 is $75 \%$ volume, and Group 3 is $50 \%$ volume.

Figure 2. These changes were considered temporary because follow-up testing showed that the thresholds reverted to their premusic exposure levels within a week.

\section{DPOAE Results}

Shifts in DPOAEs were assessed at the following frequencies: $499,1003,1409,2000,2822,3991$, and $5649 \mathrm{~Hz}$ (Figure 3). Significant shifts were found only in Group 1 at frequencies 2000 and $2822 \mathrm{~Hz}$. Further details on the statistical analysis are described in the following paragraphs.

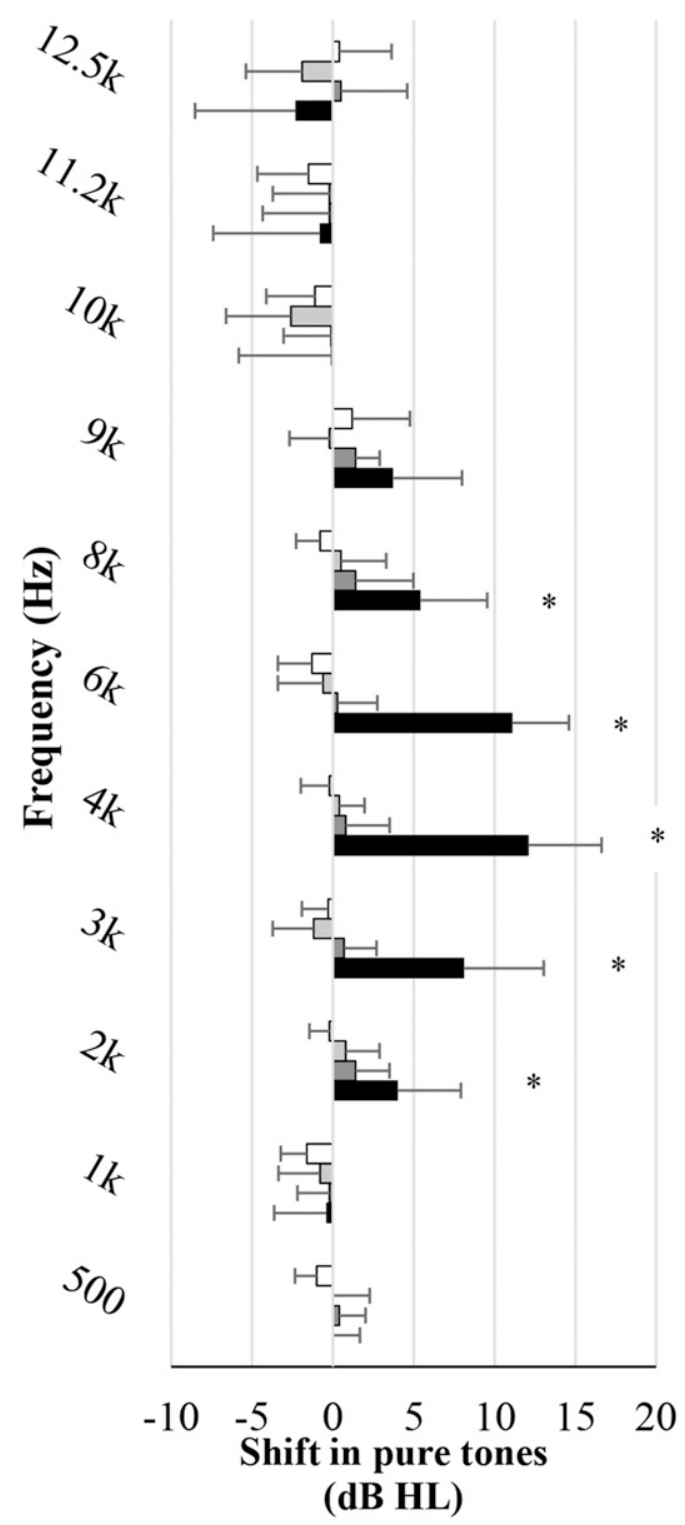

\section{$\square$ Control Group $\square 50 \%$ Volume \\ $75 \%$ Volume $\quad 100 \%$ Volume}

Figure 2. Shift in pure-tone thresholds (postmusic exposure minus premusic exposure) averaged across right and left ears. Significant increase in thresholds was obtained only for Group 1 at 2, $3,4,6$, and $8 \mathrm{kHz}$. Group 1 is $100 \%$ volume, Group 2 is $75 \%$ volume, and Group 3 is $50 \%$ volume.

\section{Statistical Analyses}

The outcome measures used in the analysis to identify significant differences between pre- and postmusic exposure test results were changes (shifts) in pure-tone thresholds (dB HL) and DPOAEs (dB SPL). These measures were grouped into three categories. The first category consisted of seven measures: pure-tone threshold shifts at 500 $\mathrm{Hz}, 1,2,3,4,6$, and $8 \mathrm{kHz}$. The second category consisted of four measures: pure-tone threshold shifts at 9, 10, 11.2, 

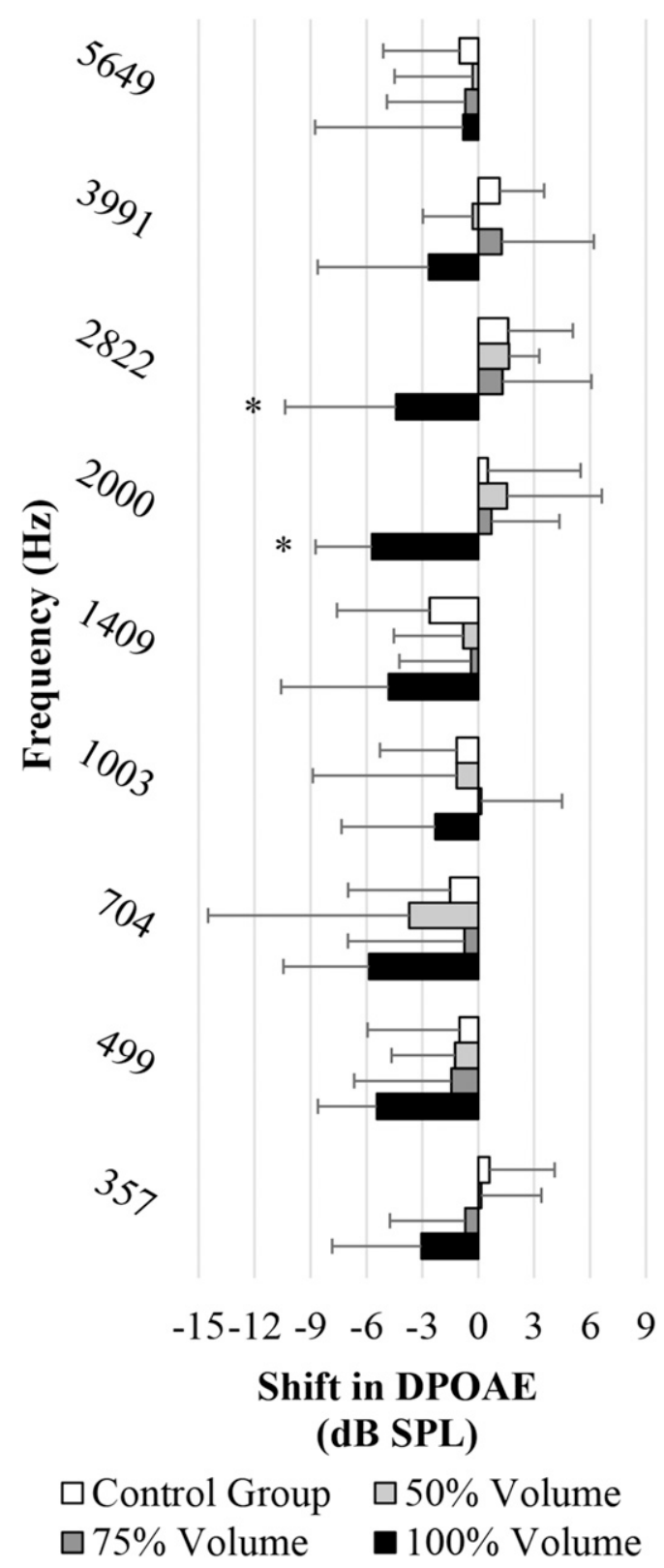

Figure 3. Shift in DPOAE data (postmusic exposure minus premusic exposure) averaged across right and left ears. Significant decrease in DPOAEs were obtained only for Group 1 at 2000 and $2822 \mathrm{~Hz}$. Group 1 is $100 \%$ volume, Group 2 is 75\% volume, and Group 3 is $50 \%$ volume.

and $12.5 \mathrm{kHz}$. The third category consisted of seven measures: DPOAE changes at 499, 1003, 1409, 2000, 2822, 3991, and $5649 \mathrm{~Hz}$. Repeated measures analysis of variance (ANOVA) was performed on each category with outcome measures as the within-subject factor, and volume and gender as between-subject factors. With regard to volume levels, 0 volume (no music exposure) was set as the reference and the other three volume levels, $100 \%, 75 \%$, and $50 \%$, were set as three dummy variables. For the violation of the sphericity assumption in the covariance matrix, the $p$-values were adjusted using Greenhouse-Geisser or Huynh-Feldt-Lecoultre correction. Summarized ANOVA results from all three categories of measures are shown in Tables 2 and 3 .

Category 1 (Pure-Tone Thresholds at $500 \mathrm{~Hz}, 1,2$, $3,4,6$, and $8 \mathrm{kHz}$ )

There was no evidence of any interaction between volume and gender; hence, these were excluded from the model. The ANOVA analysis showed that the volume was highly significant for the measures in this category; however, gender was not significant (Table 2). The effect of interaction between test frequency and gender was not significant after adjusting for assumption violation in the covariance matrix using either Greenhouse-Geisser or Huynh-Feldt-Lecoultre correction. The effect of frequency and the interaction between frequency and volume were highly significant, which meant that the main effect of volume varied depending on the frequency (Table 3).

The individual effects of different volume levels (setting zero as reference) for each frequency were then analyzed. As expected from the ANOVA results depicting the interaction between frequency and volume, it was found that the effect of volume indeed changed depending on the frequency in question. However, a consistent theme was that the strongest effect of volume on auditory thresholds was at $100 \%$ volume level. Even after correcting for multiple testing, auditory thresholds were significantly poorer after listening to music at $100 \%$ volume at frequencies $2,3,4,6$, and $8 \mathrm{kHz}$. Below is the interaction plot (Figure 4) and regression coefficients for the statistically significant outcome measures (Table 4).

Category 2 (Pure-Tone Thresholds at 9, 10, 11.2, and $12.5 \mathrm{kHz}$ )

Because there was no evidence of any interaction between volume and gender, it was excluded from the model. Table 2 shows that volume and gender are not significant for the measures in this category. Among the within-subjects factors, only frequency was significant. The effect of interaction between frequency with volume and gender were not significant after adjusting for assumption violation in the covariance matrix using either Greenhouse-Geisser or Huynh-Feldt-Lecoultre correction.

When individual effects of different volume levels (setting zero as reference) for each frequency were scrutinized, it was found that because of the lack of significance of the overall between-subject factors, results for individual frequencies did not show any statistical significance and are thus not presented here. 
Table 2. Repeated Measures ANOVA Results for between Subjects

\begin{tabular}{|c|c|c|c|c|c|c|}
\hline Source & Category & DF & Type III SS & Mean Square & F Value & $\mathrm{Pr}>\mathrm{F}$ \\
\hline \multirow[t]{3}{*}{ Volume } & Category 1 & 3 & $1,858.200000$ & 619.400000 & 35.23 & $<0.0001$ \\
\hline & Category 2 & 3 & 60.525000 & 20.175000 & 0.40 & 0.7536 \\
\hline & Category 3 & 3 & 696.588393 & 232.196131 & 4.58 & 0.0083 \\
\hline \multirow[t]{3}{*}{ Gender } & Category 1 & 1 & 18.514286 & 18.514286 & 1.05 & 0.3118 \\
\hline & Category 2 & 1 & 90.000000 & 90.000000 & 1.79 & 0.1901 \\
\hline & Category 3 & 1 & 4.758036 & 4.758036 & 0.09 & 0.7611 \\
\hline \multirow[t]{3}{*}{ Error } & Category 1 & 35 & 615.342857 & 17.581224 & & \\
\hline & Category 2 & 35 & $1,763.950000$ & 50.398571 & & \\
\hline & Category 3 & 35 & $1,774.145536$ & 50.689872 & & \\
\hline
\end{tabular}

Category 1 includes pure-tone changes for frequencies $500 \mathrm{~Hz}, 1,2,3,4,6$, and $8 \mathrm{kHz}$. Category 2 includes pure-tone changes for frequencies 9, 10, 11.2, and $12.5 \mathrm{kHz}$. Category 3 includes DPOAE changes for frequencies 499, 1003, 1409, 2000, 2822, 3991 , and 5649 Hz.

Category 3 (DPOAE Changes at 499, 1003, 1409, 2000, 2822, 3991, and $5649 \mathrm{~Hz}$ )

Again, there was no evidence of any interaction between volume and gender; hence, these were excluded from the model. Table 2 shows volume to be highly significant. Frequency showed no main effect. The interactions between frequency and volume, and frequency and gender were also found to not be significant.

Following this, individual effects of different volume levels (setting zero as reference) for each frequency were scrutinized. After correcting for multiple testing, statistical significance at maximum level (100\%) was found only for DPOAEs at 2000 and $2822 \mathrm{~Hz}$. Hence, for this category of measurements, the effect of volume is weak at best (Table 4).

In summary, we find that the effects are the most dominant for Category 1 outcomes. However, one interesting finding from the analysis is the fact that most of the results are consistently in one direction for Group 1 (100\% volume level), even when not significant.

\section{DISCUSSION}

$\mathrm{P}$ AS are capable of producing high sound levels that can lead to hearing loss (Portnuff, 2016). This may have led to a higher prevalence of hearing loss in subjects that listen to their PAS devices (Peng et al, 2007; Montoya et al, 2008; Figueiredo et al, 2011; Le Prell et al, 2011; 2012; 2013; Sulaiman et al, 2013; Keppler et al, 2015; Kumar and Deepashree, 2016). Earlier studies have reported PAS usage at high-volume settings among 37-95\% of the listeners (Torre, 2008; Vogel et al, 2008; Hodgetts et al, 2009; Hoover and Krishnamurti 2010). Jiang et al (2016), in their review paper on PAS usage and hearing loss in adolescents and young adults, concluded that up to $58 \%$ of listeners exceeded $100 \%$ of the daily noise dose, especially in background noise. They also reported significantly worse hearing thresholds and weaker otoacoustic emissions in PAS users. In terms of frequencies affected, long-term use of PAS has shown to exhibit hearing loss at clinical frequencies (Kim et al, 2009; Le Prell et al, 2011), extended high frequencies (Le Prell et al, 2013; Sulaiman et al, 2013), or both (Peng et al, 2007).

Several studies have also reported weaker otoacoustic emissions in this population (Montoya et al, 2008; Figueiredo et al, 2011; Le Prell et al, 2012; Kumar and Deepashree, 2016). An earlier study by Sulaiman et al (2013) reported that young PAS users who listened to

Table 3. Repeated Measures ANOVA Results for within Subjects

\begin{tabular}{|c|c|c|c|c|c|c|}
\hline Source & Category & $\mathrm{DF}$ & Type III SS & Mean Square & $F$ Value & Adj $\operatorname{Pr}>F$ \\
\hline \multirow[t]{3}{*}{ Frequency } & Category 1 & 6 & 469.242857 & 78.207143 & 12.46 & $<0.0001$ \\
\hline & Category 2 & 3 & 167.4750000 & 55.8250000 & 7.31 & 0.0007 \\
\hline & Category 3 & 6 & 198.837500 & 33.139583 & 1.62 & 0.1676 \\
\hline \multirow[t]{3}{*}{ Frequency $\times$ Volume } & Category 1 & 18 & $1,089.300000$ & 60.516667 & 9.64 & $<0.0001$ \\
\hline & Category 2 & 9 & 136.9750000 & 15.2194444 & 1.99 & 0.0659 \\
\hline & Category 3 & 18 & 288.605357 & 16.033631 & 0.78 & 0.6751 \\
\hline \multirow[t]{3}{*}{ Frequency $\times$ Gender } & Category 1 & 6 & 81.785714 & 13.630952 & 2.17 & 0.0886 \\
\hline & Category 2 & 3 & 18.7000000 & 6.2333333 & 0.82 & 0.4617 \\
\hline & Category 3 & 6 & 78.298214 & 13.049702 & 0.64 & 0.6474 \\
\hline \multirow[t]{3}{*}{ Error (Frequency) } & Category 1 & 210 & $1,317.957143$ & 6.275986 & & \\
\hline & Category 2 & 105 & 801.3500000 & 7.6319048 & & \\
\hline & Category 3 & 210 & $4,294.473214$ & 20.449872 & & \\
\hline
\end{tabular}




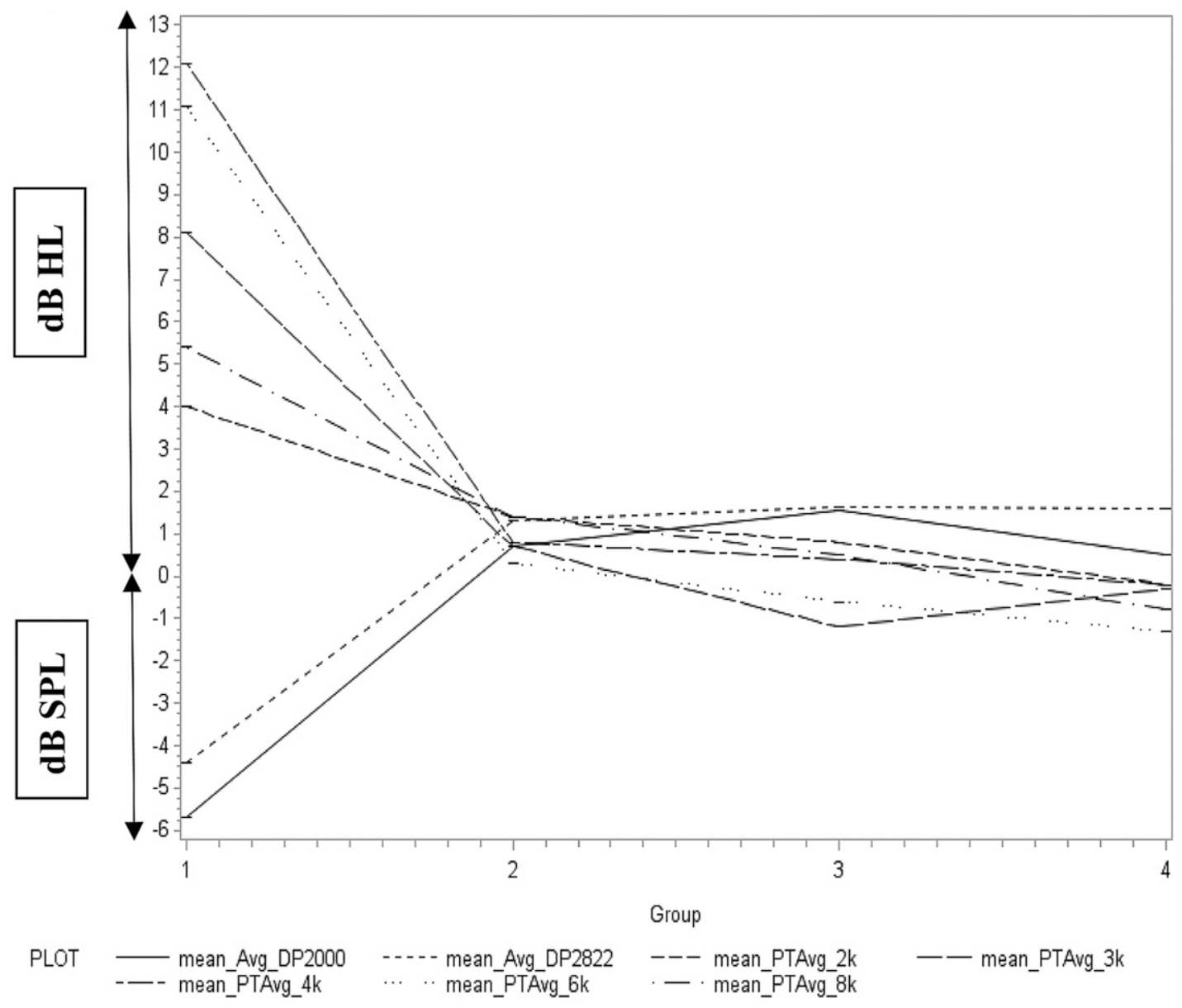

Figure 4. Interaction plot and regression coefficients for the seven significant outcome measures.

more than 1 hour/day at higher than $50 \%$ volume setting had worse thresholds for TEOAE and DPOAE results, as well as poorer extended high-frequency thresholds. Bhagat and Davis (2008) found that normalhearing adults exposed to $30 \mathrm{~min}$ of music through MP3 players, set at an average level of $85 \mathrm{dBC} \pm$ $3 \mathrm{~dB}$, showed significantly reduced DPOAEs in halfoctave bands centered around 1400-6000 Hz. They described this reduction in DPOAEs as a possible early indication of cochlear hair cell damage.
Although the listening devices examined and research protocols used across research studies are different, the consensus is that listening to loud music through PAS for long durations can lead to hearing loss. Audiologists are often asked about safe listening levels and optimum listening durations for various PAS in the market. There are no simple answers to these questions because there are so many different choices of PAS devices, earphone types, and listening habits. When the wide variety of music genre and individual susceptibility

Table 4. Regression Coefficients of the Different Volume Levels Relative to Volume Zero for Each of the Significant Outcomes

\begin{tabular}{lccc}
\hline Outcomes & Volume 50\% & Volume 75\% & Volume 100\% \\
\hline Avg_DP2000 & 1.05 & 0.2 & $-6.20(0.004)$ \\
Avg_DP2822 & 0.05 & -0.3 & $-6.00(0.005)$ \\
PTAvg_2k & 1.00 & 1.60 & $4.20(0.001)$ \\
PTAvg_3k & -0.90 & 1.00 & $8.40(<0.0001)$ \\
PTAvg_4k & 0.60 & 1.00 & $12.30(<0.0001)$ \\
PTAvg_6k & 0.70 & 1.60 & $12.40(<0.0001)$ \\
PTAvg_8k & 1.30 & 2.20 & $6.20(0.0002)$ \\
\hline
\end{tabular}

The $p$-values for coefficients that are significant are included in parenthesis. 
are added to this equation, the issue gets even more complex. We undertook this experimental investigation to find some practical solution to this complex problem.

The purpose of this study was to identify if people listening to music with an iPod at high volume levels are at risk for hearing loss. The temporary shifts in puretone thresholds and DPOAEs were used as test measures for assessing the risk of developing hearing loss with the iPod volume set at $100 \%, 75 \%, 50 \%$, or $0 \%$ (no music exposure). Music exposure levels were first determined on a KEMAR using a standard playlist of current popular songs. In addition, real-ear measures were obtained while the subjects listened to the playlist during the experimental condition. A sound-field equivalent correction factor was applied to the real-ear measures obtained on the subjects. This accounted for the measurements made in the subject's ear canal, close to the eardrum, as opposed to outside the head (Shotland, 1996; Hammershøi, 2007; Keith et al, 2008; Fligor, 2009a,b). After real-ear measures were made and correction factors applied, the $\mathrm{dBA}$ values obtained for the playlist were found to be highly comparable with the measurements made on the KEMAR in $\mathrm{dBC}$ values (as required by the IRB).

The present findings indicate that listening through an iPod to the selected playlist for $30 \mathrm{~min}$ at $100 \%$ volume leads to significant changes in auditory test measures compared with other volume levels. Auditory test measures obtained with $75 \%$ and $50 \%$ volume levels for 30 min were not significantly different from the $0 \%$ level (the no music exposure condition), indicating no foreseeable risks when the volume is set at or below $75 \%$. With $100 \%$ volume setting, TTS were seen at frequencies ranging from 2000 to $8000 \mathrm{~Hz}$. However, extended high frequencies $(9-12.5 \mathrm{kHz})$ and lower frequencies $(500$ and $1000 \mathrm{~Hz})$ did not show significant shifts. Our study also revealed significantly weaker DPOAEs at 2000 and $2822 \mathrm{~Hz}$ in subjects that listened to the music at $100 \%$ volume level. The variability with DPOAE measures was much greater than for puretone measures. Nevertheless, it should be noted that even with the high variability in DPOAEs, the results were all in one direction for the $100 \%$ volume group (i.e., weaker emissions following music exposure at all frequencies).

PAS have changed over the years; however, it is interesting to see how the present findings are fairly consistent with some of the earlier studies that set out to identify risky listening behavior with PAS usage. Fligor and Cox (2004) investigated the output levels from many commercially available portable compact disc players in combination with several styles of headphones on a KEMAR. They found that output levels varied across devices, with peak sound pressure levels exceeding $130 \mathrm{~dB}$ SPL at times. Based on the recommendations from NIOSH, the authors concluded that the maximum permissible noise dose could be typically reached within one hour of listening when the volume is set at $70 \%$. They indicated that reasonable guidelines would limit supra-aural headphone use to one hour or less per day with a volume set at $60 \%$. Trzaskowski et al (2014) found no significant changes in pure tones, TEOAE, or DPOAE results in their participants that listened to $30 \mathrm{~min}$ of a looped audio track at an overall intensity level of 86.6 dBA. Portnuff and Fligor (2006) evaluated five MP3 players from three different manufacturers with stock earbuds and four additional models of earphones with each player, measured across five popular music genres. They reported that for maximum volume settings, periods of up to $18 \mathrm{~min} /$ day were safe. Regardless of earphone type, no limit was recommended at volume-control settings below $60 \%$, but for higher volume settings, specific limits ranged from 3 min to 20 hours, depending on the type of earphone. They also reported no significant differences across genres of music. Hodgetts et al (2007) reported that the maximum output levels of the MP3 player they studied could be used for only 1-15 min/day with earbuds and supra-aural earphones. Fligor (2009b) suggested a rule of thumb that limits the volume control of earbuds to $80 \%$ of maximum, if the listening time is $90 \mathrm{~min}$ or less per day.

Limitations of the study: There is the possibility of slit leaks at lower frequencies during our real-ear measurements, similar to those seen in real-ear-tocoupler differences during hearing aid fittings (Dillon, 2012). There is often a propensity to have slit leaks between the ear canal wall and a hard surface such as an earmold or earbud. Dillon (2012) showed that slit leaks can often account for differences in sound pressure level at 250 and $500 \mathrm{~Hz}$. Second, available equipment forced the real-ear recordings to be consecutive rather than simultaneous, meaning that songs were sampled at different points during each song for right and left ears. This may have led to slight differences in overall dBA across samples between right and left ears. Another limitation is that silent periods of less than one second were not avoided, and these silent periods may have allowed for some recovery. The rationale for truncating silent intervals of more than one second was to provide continuous listening experience and avoid having breaks or long pauses between songs during the 30-min exposure. It must be noted, however, that in real life, songs/playlists have a wide variety of silent periods within and between songs and cannot be completely simulated in an experimental setup.

\section{CONCLUSION}

A s the objective of this study was to provide operational information on safe listening volume 
settings for music listening, it was concluded that for the playlist used in this study, $100 \%$ volume is not a safe level of exposure for $30 \mathrm{~min}$ or more. Listening at $75 \%$ volume or lower is considered safe for the conditions used in this study. It is difficult to provide a more specific cutoff level because of a variety of inherent combinations that can possibly occur with different types of PAS and transducers in the ever-changing market, as well as the type of music that people listen to. Despite these challenges, the outcomes in this study clearly indicate that when in-the-ear levels reach $97 \mathrm{dBA}$, as with the $100 \%$ volume setting in this study, even 30 min of exposure can produce TTS in the average listener. The results of this study are even more significant in light of the findings from Kujawa and Liberman (2009), which indicate that TTS sets up the stage for permanent auditory neural system damage. It must be emphasized that these findings are applicable only for the specific PAS device and playlist used in this study. Although this study included additionally compressed music, it is known that recording engineers routinely apply compression in music recordings so that overall levels within and across songs are not highly variable (Hodgetts et al, 2007). Because this study provides guidance on volume control settings on a popular PAS, we are hopeful that these results will aid in setting guidelines and standards for listening devices, and promote healthy listening habits among young adults.

\section{REFERENCES}

Balanay JAG, Kearney GD. (2015) Attitudes toward noise, perceived hearing symptoms, and reported use of hearing protection among college students: influence of youth culture. Noise Health 17:394-405.

Bhagat SP, Davis AM. (2008) Modification of otoacoustic emissions following ear-level exposure to MP3 player music. Int J Audiol 47: 751-760.

Bulbul SF, Muluk NB, Çakir EP, Tufan E. (2009) Subjective tinnitus and hearing problems in adolescents. Int J Pediatr Otorhinolaryngol 73:1124-1131.

Chung JH, Des Roches CM, Meunier J, Eavey RD. (2005) Evaluation of noise-induced hearing loss in young people using a web-based survey technique. Pediatrics 115:861867.

Danhauer JL, Johnson CE, Byrd A, DeGood L, Meuel C, Pecile A, Koch LL. (2009) Survey of college students on iPod use and hearing health. J Am Acad Audiol 20:5-27.

Danhauer JL, Johnson CE, Dunne AF, Young MD, Rotan SN, Snelson TA, Stockwell JS, McLain MJ. (2012) Survey of high school students' perceptions about their iPod use, knowledge of hearing health, and need for education. Lang Speech Hear Serv Sch 43:14-35.

Degeest S, Corthals P, Vinck B, Keppler H. (2014) Prevalence and characteristics of tinnitus after leisure noise exposure in young adults. Noise Health 16:26.
Derebery MJ, Vermiglio A, Berliner KI, Potthoff M, Holguin K. (2012) Facing the music: pre- and postconcert assessment of hearing in teenagers. Otol Neurotol 33:1136-1141.

Dillon H, ed. (2012) Electroacoustic performance and measurement. In Hearing Aids. Sydney: NY: Boomerang Press; Thieme, 81-126.

Eldredge DH, Mills JH, Bohne BA. (1973) Anatomical, behavioral, and electrophysiological observations on chinchillas after long exposures to noise. Adv Otorhinolaryngol 20:64-81.

Feder K, Marro L, Keith SE, Michaud DS. (2013) Audiometric thresholds and portable digital audio player user listening habits. Int $J$ Audiol 52:606-616.

Figueiredo RR, de Azevedo AA, de Oliveira PM, Pereira S, Amorim V, Rios AG, Baptista V. (2011) Incidence of tinnitus in MP3 player users. Braz J Otorhinolaryngol 77:293-298.

Fligor BJ. (2009a) Personal listening devices and hearing loss: seeking evidence of a long-term problem through a successful short-term investigation. Noise Health 11:129-131.

Fligor BJ. (2009b) Risk for noise-induced hearing loss from use of portable media players: a summary of evidence through 2008. Perspect Audiol 5:10-20.

Fligor BJ. (2011) Recreational NIHL: a summary of the evidence. http://www.audiologyonline.com/articles/recreational-nihl-summaryevidence-800. Accessed October 15, 2016.

Fligor BJ, Cox LC. (2004) Output levels of commercially available portable compact disc players and the potential risk to hearing. Ear Hear 24:513-527.

Fligor BJ, Levey S, Levey T. (2014) Cultural and demographic factors influencing noise exposure estimates from use of portable listening devices in an urban environment. J Speech Lang Hear Res 57:1535-1547.

Gilles A, De Ridder D, Van Hal G, Wouters K, Punte AK, Van de Heyning P. (2012) Prevalence of leisure noise-induced tinnitus and the attitude toward noise in university students. Otol Neurotol 33:899-906.

Gilles A, Van Hal G, De Ridder D, Wouters K, Van de Heyning P. (2013) Epidemiology of noise-induced tinnitus and the attitudes and beliefs towards noise and hearing protection in adolescents. PLoS One 8(e70297):1-8.

Goggin LS, Eikelboom RH, Edwards GS, Maric V, Anderson JR, Sander PB, James MA, Ricciardo PM, Broeze C, Atkins L, Rajan GP. (2008) Noise levels, hearing disturbances, and use of hearing protection at entertainment venues. Aust New Zealand J Audiol 30:50-58.

Gopal KV, Chesky K, Beschoner EA, Nelson PD, Stewart BJ. (2013) Auditory risk assessment of college music students in jazz band-based instructional activity. Noise Health 15:246-252.

Haahr M. (2016) Random.org: true random number generator. Randomness and Integrity Services Ltd. http://www.random.org. Accessed October 12, 2016.

Hammershøi D. (2007) Manikin for assessment of MP3 player exposure. 19th International Congress on Acoustics. Aalborg, Denmark. September 2-7, 2007.

Hanson DR, Fearn RW. (1975) Hearing acuity in young people exposed to pop music and other noise. Lancet 306:203-205.

Henderson D, Bielefeld EC, Harris KC, Hu BH. (2006) The role of oxidative stress in noise-induced hearing loss. Ear Hear 27: $1-19$. 
Henderson E, Testa MA, Hartnick C. (2011) Prevalence of noiseinduced hearing-threshold shifts and hearing loss among US youths. Pediatrics 127:e39-e46.

Hodgetts WE, Rieger JM, Szarko RA. (2007) The effects of listening environment and earphone style on preferred listening levels of normal hearing adults using an MP3 player. Ear Hear 28: 290-297.

Hodgetts W, Szarko R, Rieger J. (2009) What is the influence of background noise and exercise on the listening levels of iPod users? Int J Audiol 48:825-832.

Holland III NV. (2008) Sound pressure levels measured in a university concert band: a risk of noise-induced hearing loss? Update Appl Res Music Educ 27:3-8.

Hoover A, Krishnamurti S. (2010) Survey of college students' MP3 listening: habits, safety issues, attitudes, and education. $A m J$ Audiol 19:73-83.

Jiang W, Zhao F, Guderley N, Manchaiah V. (2016) Daily music exposure dose and hearing problems using personal listening devices in adolescents and young adults: a systematic review. Int $J$ Audiol 55:197-205.

Keith SE, Michaud DS, Chiu V. (2008) Evaluating the maximum playback sound levels from portable digital audio players. J Acoust Soc Am 123:4227-4237.

Keppler H, Dhooge I, Vinck B. (2015) Hearing in young adults. Part II: the effects of recreational noise exposure. Noise Health $17: 245-252$

Kim MG, Hong SM, Shim HJ, Kim YD, Cha CI, Yeo SG. (2009) Hearing threshold of Korean adolescents associated with the use of personal music players. Yonsei Med $J$ 50:771-776.

Kujawa SG, Liberman MC. (2009) Adding insult to injury: cochlear nerve degeneration after "temporary" noise-induced hearing loss. J Neurosci 29:14077-14085.

Kumar A, Mathew K, Alexander SA, Kiran C. (2009) Output sound pressure levels of personal music systems and their effect on hearing. Noise Health 11:132-140.

Kumar UA, Deepashree SR. (2016) Personal music systems and hearing. J Laryngol Otology 130:717-729.

Le Prell CG, Hensley BN, Campbell KCM, Hall III JW, Guire K. (2011) Evidence of hearing loss in a "normally-hearing" collegestudent population. Int J Audiol 50:S21-S31.

Le Prell CG, Dell S, Hensley B, Hall III JW, Campbell KC, Antonelli PJ, Green GE, Miller JM, Guire K. (2012) Digital music exposure reliably induces temporary threshold shift (TTS) in normal hearing human subjects. Ear Hear 33:e44-e58.

Le Prell CG, Spankovich C, Lobariñas E, Griffiths SK. (2013) Extended high-frequency thresholds in college students: effects of music player use and other recreational noise. J Am Acad Audiol 24:725-739.

LePage EL, Murray NM. (1998) Latent cochlear damage in personal stereo users: a study based on click-evoked otoacoustic emissions. Med J Aust 169:588-592.

Levey S, Levey T, Fligor BJ. (2011) Noise exposure estimates of urban MP3 player users. J Speech Lang Hear Res 54:263-277.

Liberman MC, Kujawa SG. (2017) Cochlear synaptopathy in acquired sensorineural hearing loss: manifestations and mechanisms. Hear Res 349:138-147.
Lonsbury-Martin BL, Martin GK, Bohne BA. (1987) Repeated TTS exposures in monkeys: alterations in hearing, cochlear structure, and single-unit thresholds. J Acoust Soc Am 81:1507-1518.

McNeill K, Keith SE, Feder K, Konkle ATM, Michaud DS. (2010) MP3 player listening habits of 17 to 23-year-old university students. J Acoust Soc Am 128:646-653.

Montoya FS, Ibargüen AM, Vences AR, del Rey AS, Sanchez Fernandez JM. (2008) Evaluation of cochlear function in normalhearing young adults exposed to MP3 player noise by analyzing transient evoked otoacoustic emissions and distortion products. Otolaryngol Head Neck Surg 37:718-724.

Muchnik C, Amir N, Shabtai E, Kaplan-Neeman R. (2012) Preferred listening levels of personal listening devices in young teenagers: self reports and physical measurements. Int J Audiol 51:287-293.

Muhr P, Rosenhall U. (2010) Self-assessed auditory symptoms, noise exposure, and measured auditory function among healthy young Swedish men. Int J Audiol 49:317-325.

National Institute for Occupational Safety and Health (NIOSH). (1998) Occupational Noise Exposure: Revised Criteria 1998. U.S. Department of Health and Human Services. Cincinnati, OH.

Peng JH, Tao ZZ, Huang ZW. (2007) Risk of damage to hearing from personal listening devices in young adults. $J$ Otolaryngol $36: 179-183$.

Portnuff CD. (2016) Reducing the risk of music-induced hearing loss from overuse of portable listening devices: understanding the problems and establishing strategies for improving awareness in adolescents. Adolesc Health Med Ther 10:27-35.

Portnuff C, Fligor BJ. (2006) Sound output levels of the iPod and other MP3 players: is there potential risk to hearing? Paper Presented at Conference on Noise-induced Hearing Loss in Children at Work and Play, Cincinnati, OH. October 19-20, 2006.

Portnuff C, Fligor BJ, Arehart KH. (2013) New measurement techniques for portable listening devices: technical report. J Audio Eng Soc 61(10):1-6.

Pugsley S, Stuart A, Kalinowski J, Armson J. (1993) Changes in hearing sensitivity following portable stereo system use. Am $J$ Audiol 2:64-67.

Rawool VW. (2012) Noise control and hearing conservation in nonoccupational settings. In Rawool VW, ed. Hearing Conservation: In Occupational, Recreational, Educational, and Home Settings. New York, NY: Thieme, 224-241.

Ryan A, Bone RC. (1978) Noise-induced threshold shift and cochlear pathology in the Mongolian gerbil. J Acoust Soc Am 63: 1145-1151.

Ryan A, Kujawa SG, Hammill TL, Le Prell C, Kil J. (2014) Temporary and Permanent Noise-Induced Threshold Shifts [guidelines]. Pharmaceutical Interventions for Hearing Loss. http:// hearing.health.mil/EducationAdvocacy/Newsletters.aspx. Accessed July 2016.

Serra MR, Biassoni EC, Richter U, Minoldo G, Franco G, Abraham S, Carignani JA, Joekes S, Yacci MR. (2005) Recreational noise exposure and its effects on the hearing of adolescents. Part I: an interdisciplinary long-term study. Int $J$ Audiol 44:65-73.

Shotland LI. (1996) Dosimetry measurements using a probe tube microphone in the ear canal. J Acoust Soc Am 99:979-984.

Silvestre RAA, Ribas Â, Hammerschmidt R, de Lacerda ABM. (2016) High-frequency profile in adolescents and its relationship 
with the use of personal stereo devices. J Pediatr (Rio J) 92: 206-211.

Spankovich C, Griffiths SK, Lobarinas E, Morgenstein KE, De la Calle S, Ledon V, Guercio D, Le Prell CG. (2014) Temporary threshold shift after impulse-noise during video game play: laboratory data. Int J Audiol 53:S53-S65.

Sulaiman AH, Husain R, Seluakumaran K. (2013) Evaluation of early hearing damage in personal listening device users using extended high-frequency audiometry and otoacoustic emissions. Eur Arch Otorhinolaryngol 271:1463-1470.

Torre III P (2008) Young adults' use and output level settings of personal music systems. Ear Hear 29:791-799.

Trask DK, Abkas B, Jous N. (2006) R111: listening habits and noise exposure of MP3 player users. Otolaryngol Head Neck Surg 135:P142-P143.

Tronstad TV, Gelderblom FB. (2016) Sound exposure during outdoor music festivals. Noise Health 18:220-228.

Trzaskowski B, Jẹdrzejczak WW, Piłka E, Cieślicka M, Skarżyński H. (2014) Otoacoustic emissions before and after listening to music on a personal player. Med Sci Monit 20: $1426-1431$.
Vogel I, Brug J, Hosli EJ, Van Der Ploeg CP, Raat H. (2008) MP3 players and hearing loss: adolescents' perceptions of loud music and hearing conservation. J Pediatr 152:400-404.

Vogel I, Verschuure H, Van Der Ploeg CPB, Brug J, Raat H. (2010) Estimating adolescent risk for hearing loss based on data from a large school-based survey. Am J Public Health 100:1095-1100.

Vogel I, Brug J, Van Der Ploeg CP, Raat H. (2011) Adolescents risky MP3-player listening and its psychosocial correlates. Health Educ Res 26:254-264.

Washnik NJ, Phillips SL, Teglas S. (2016) Student's music exposure: full-day personal dose measurements. Noise Health 18:98-103.

Williams W. (2005) Noise exposure levels from personal stereo use nivel de expositión a ruido por el uso de estéreos personales. Int $J$ Audiol 44:231-236.

World Health Organization. (2015) 1.1 Billion People at Risk of Hearing Loss: WHO highlights serious threat posed by exposure to recreational noise. http://www.who.int/mediacentre/news/ releases/2015/ear-care/en/. Accessed October 2015.

Zocoli AM, Morata TC, Marques JM, Corteletti LJ. (2009) Brazilian young adults and noise: attitudes, habits, and audiological characteristics. Int J Audiol 48:692-699. 


\section{APPENDIX: Music Exposure Questionnaire}

1. What type of device do you use to listen to music with earphones? (Circle all that apply)

Android Phone

Apple iPhone

Apple iPod

Other (please specify)

2. What type of earphones do you use while listening to music on your device? (Circle all that apply)
Apple Earbuds
Other Earbuds
Headphones
In-canal earphones
Other (please specify)

3. How many years have you listened to music through any device?

$<1$ year

$1-2$ years

3-4 years

$>5$ years

4. How many times a week do you listen to your device?

Less than once a week

1 time per week

2 times per week

3-4 times per week

5-6 times per week

Other (please specify)

5. How many hours do you spend listening to music per week?

$<1$ hour

1 hour

2 hours

$3-4$ hours

Other (please specify)

6. What is the number of maximum time you continuously listen to music (i.e., without breaks) in a typical week at maximum volume?

$<30$ min

$30 \mathrm{~min}$

1 hour

2 hours

$3-4$ hours

Other (please specify)
7. What have you experienced (circle all that apply) after listening to music through your device?

Ringing/buzzing in ears

Ear fullness

Hearing loss/muffled hearing

Soreness of ears

Limited concentration

Decreased tolerance or annoyance with certain environmental sounds (hyperacusis)

None of these

8. During which activities (circle all that apply) do you listen to music through your device?

Studying

Sleeping

Riding on a bus, train, or plane

Driving

Walking/Jogging

Bike Riding

Exercising

Working

Other (please specify)

9. Have you listened to loud music at maximum level on your iPod in the last 24 hours?

Yes

No

10. Have you been exposed to loud noise such as machinery, lawn mower, concerts, etc., in the last 24 hours?

Yes

No

11. Are you concerned about hearing loss from listening to your devise?

Not concerned

Slightly concerned

Moderately concerned

Extremely concerned

12. Would you be willing to turn down the volume of your iPod to prevent damaging your ears?

Yes

No

13. Would you be willing to decrease the amount of time you listen to your iPod to protect your hearing if advised regarding the risk of hearing loss?

Yes

No 
14. What do you think would be the best way to provide information on hearing loss to the public? (Circle all that apply)

Family/friends

School

Magazines

Radio

Mail

Internet

Audiologists

Family Doctor

Other (please specify)
15. If there was a Web site that provided information on listening devices, what topic would be most important to include?

Appropriate volume levels

Earphone type

Ideal environments for listening

Interference with communication or personal safety

Adapted and modified from Hoover and Krishnamurti (2010), and Danhauer et al (2009). 